\title{
TOWARDS AN ABSORPTION STRATEGY FOR THE MANAGEMENT OF FLOOD RISK: STUDY OF THE STRATEGY OF RESISTANCE AND THE ARTIFICIALIZATION OF SOILS IN THE FRANCO-BELGIAN CROSS-BORDER TERRITORY
}

\author{
EMELINE COSZACH ${ }^{1}$, VINCENT BECUE ${ }^{1}$, JÉRÉMY CENCI $^{1}$, ISABELLE DE SMET ${ }^{1}$, \\ SMAIL KHAINAAR ${ }^{2}$, PATRIZIA LAUDATI ${ }^{3} \&$ CÉDRIC RIVIÈRE $^{1}$ \\ ${ }^{1}$ Faculté d'Architecture et d'Urbanisme de l'Université de Mons, France \\ ${ }^{2}$ Laboratoire DeViSu de l'Université Polytechnique Hauts-de-France, France \\ ${ }^{3}$ Laboratoire SIC.Lab de l'Université Côte d'Azur, France
}

\begin{abstract}
Historically, civilizations have settled near streams, rivers and seas. These territories offer a strategic position for the development of trade and transport, an ideal relief for the development of cities and fertile soils, favorable to crops. Idyllic picture if we forget their strong vulnerability in the face of rising waters. Indeed, by this choice of location, humans are also subject to the risk of flooding. Over the course of experienced disasters, human societies have developed protective measures with the aim of reducing the caused damages, both human and material. In the boom of the industrial era, these measures primarily resulted from civil engineering in a strategy of resistance against water. Dams, pumping stations, outlets, pipes, etc. then emerged, exponentially, on all continents. Even though these measures have proved their worth on several occasions and over many years, they present, and in Europe as well, several significant disadvantages. Physical and visual barriers preventing direct contact with water, they have also played a major role in the artificialization of our soils and the loss of biodiversity through the drying out of certain portions of the territory. These infrastructures, legacy of our past, are no longer adequate with the new risks and challenges of the cities of the 21 st century. It is therefore necessary, in order to make our cities resilient, to adapt our management of the flooding risk currently under the symbol of water control towards the management of absorption and the "living with water". To manage this, a historical study of the development of these infrastructures but also of their impact on the territory and the landscape will be carried out with a particular focus on the FrancoBelgian cross-border territory formed by the districts of Mons and Valenciennes.
\end{abstract}

Keywords: risk, inondation, artificialization, resistance, adaptation, nature, biodiversity, Valenciennes, Mons.

\section{INTRODUCTION}

Water is an essential component for human life, for the development of ecosystems and societies. It is therefore quite natural that since immemorial time, civilizations have settled near streams, rivers and seas. Source of supply and recreation, these territories also offer a strategic position for the development of trade and transport, an ideal terrain for the development of cities as well as rich soils, favorable to crops. An idyllic picture if we forget their high vulnerability to rising water levels.

Indeed, as Terrin [1] explains, the relationships maintained by human societies with regard to water have long exhibited a certain puzzling ambivalence. Sometimes tinged with horror, fear and sadness when men are abandoned idle, sometimes with no more family, culture, livestock or even property. Sometimes tinged with joy and prospect when the land is made fertile and prosperous, suitable to the development of agriculture. First maintained by mythological stories, this dual attitude of societies towards aquatic environments continues to this day. Man is divided between on the one hand the unforeseeable and difficult to 
measure danger that they represent and on the other hand, the unshakeable attraction to water landscapes and their proximity [1].

The concept of flood risk management is relatively recent. But very quickly, on all continents, human communities have continued to develop, throughout disasters, adaptive capacities allowing them to live as close as possible to water, despite the risk that this represents [1]. Rising groundwater, soil liquefaction, subsidence, flooding of rivers, storm surges, torrential rains, ... flooding can be extremely variable in nature. Although it was used at one time as a military strategy to push back enemy troops [2], it is generally the result of natural phenomena. While traditional cultures have rather turned to adaptive strategies, Western communities have focused on the culture of zero risk [1]. In the boom of the industrial era, these measures will result mainly from civil engineering in a strategy of water resistance. Dams, pumping stations, outlets, pipes, ... will then emerge, exponentially.

Although these measures have proven their worth over and over again for many years, they nevertheless have certain major disadvantages. Physical and visual barriers preventing close contact with water, they have also played a major role in the artificialization of our soils and the loss of biodiversity through the drying up of certain portions of the territory. An insidious utopia to have put an end to natural hazards and to be able to disregard the risk without any consequence according to Bauduceau [3], the natural disasters that have occurred in recent years have sadly reminded us of the growing vulnerabilities of this technology as time goes by.

Thus, these infrastructures, legacy of our past, are no longer up to the new risks and challenges of the cities of the 21 st century. It is therefore necessary, in order to make our cities resilient, to adapt our management of the risk of flooding currently under the acronym of water mastery towards management of water absorption and "living with water" with a particular focus on the planning of our territories.

But what is this "resist" flood management strategy and what are these limits that we are talking about? What are the consequences for our territories and human societies, but above all, the possible ways of adaptation for an inclusive risk management? What about the specific territory formed by the districts of Mons and Valenciennes?

Indeed, with the objective of shedding light on the present and guiding this new risk management strategy, a historical study of the development of these infrastructures but also of their impact on the territory and landscape will be carried out with a particular focus on the Franco-Belgian cross-border territory formed by the districts of Mons and Valenciennes. To answer these questions, we will first try to determine what this flood risk management strategy based on water resistance consists of and to highlight its various limits whether they are structural, economic or social. Secondly, we will analyze the consequences that these may have had on the planification of our territories, the composition of our landscapes and the decline of biodiversity before we suggest ways of reflection and actions to develop a reconciliation strategy in terms of flood risk management. In a third and final step, we will carry out an analysis of the cross-border territory formed by the districts of Mons and Valenciennes regarding its evolution following the demergement and containment policies put in place in the two countries and regarding the place left to water.

\section{FROM A STRATEGY OF WATER MASTERY}

Societies and human activities, by their establishment in the territory, create vulnerability and inherent risk. Artificialization, urban expansion, development of industries and canals, river and rail transport, etc. all create, according to Peil [4], a new topography, a new soil and new climatic conditions which, together, disrupt the cycle of water and soil permeability; in other 
words, the place of water within this territory. These changes are responsible for the upsurge in flooding episodes and their intensity.

This urban expansion as well as the rise of the population always living as close as possible to the water only increases the stakes associated with flooding. The need to react in order to ensure the safety of populations, infrastructure and property thereby reducing their vulnerability was then felt. It was in this context that the first water resistance structures were created.

\section{1 "Resist" strategy}

The resistance strategy instinctively developed by human societies for many years is (based)founded on the base idea that "it is desirable and possible to prevent water from rivers and seas from entering exploitable and valuable territories" [3]. The objective is to remove from the whims of nature, the territories threatened by flooding and thus valorize them.

Often referred to as "fight against floodings" or "hazard control", this historical flood risk management is built essentially on the control by technique of natural events. Sometimes still well anchored in the urban policies of our contemporary society, it is established on the absolute confidence in the technology spread by an engineering culture [3].

Until then made in embankments, it is from the industrial period with the development of calculation methods and innovative materials that the engineering works will flourish [5]. All concrete-clad or almost, these boil down to three different types of infrastructure sometimes combined with each other.

The first consists in protecting oneself as well as possible from aquatic flows by setting up barriers such as dikes and dams. The second includes retention areas which are generally built upstream of inhabited areas such as basins, artificial lakes and canals. And finally, in order to allow the fastest and most effective possible evacuation of water, the third category includes evacuation works by pumping, drainage and pipes [1].

The city of Tokyo, an example in this field, has chosen to develop this strategy through the development of water barriers throughout the entire perimeter of the city and even well beyond. Continuously raised, they can, in the event of an imminent flood, be lowered and thus retain the flow of water outside the city. Other barriers, this time sliding, are also present within the city itself. By being deployed on the streets, they create a zone of refuge for all the inhabitants. Finally, the city is also equipped with a colossal drainage system made up of cylindrical reservoirs and monumental underground galleries [6].

The Netherlands, because of its position below sea level, also had to quickly put in place a flood risk management strategy. Although they have since turned away from it, water control had also been favored through the establishment of the Delta National Plan and the many dams that make it up.

\subsection{The limits of the "resist" strategy}

We cannot argue that this strategy of resistance and water mastery has already proven itself many times over and has made it possible to protect, during numerous climatic episodes, populations and properties located in vulnerable territory. However, it tends to reach its limits.

Indeed, the natural disasters that have occurred in recent years (French floods in 2019, European floods in 2016, British and French floods in 2015, East-European floods in 2014, etc.) have sadly reminded us that the risk of flooding is very real and even increasingly present and disastrous, making entire populations and territories more vulnerable. Of all these 
events, it was Hurricane Katrina in 2005 in the United States that created the most stir and shook the conscience of the whole world [1]. Bordered by defensive walls and levees for nearly $550 \mathrm{~km}$ to protect it from marine and river invasions, New Orleans thinks itself out of reach and out of danger. Its urbanization has, for a non-negligible part, developed in the major bed of the river but also in areas of marshes drained by dammed canals. Thinking of being safe within his fortress, the scenario of a failure of the protection system was never imagined. When, finally, breaches form and allow water to spread over nearly $80 \%$ of the territory to heights ranging from two to four meters, the population finds itself trapped. The human and material damages are colossal; transport, energy and telecommunications networks are in jeopardy; the economy is collapsing and the unemployment rate is skyrocketing. Five years after the incident, New Orleans has yet to regain its former glory [3].

This tragic episode, among many others, made people aware of the fragility of this strategy of risk management by water mastery. These infrastructures are certainly robust and imposing but reveal several weaknesses.

The first weakness is the creation of an over-danger situation in the event of a breach of protections by generating a feeling of forgetting the risk or a feeling of overconfidence in technology. Indeed, the danger no longer being visible, a tenacious desire for urban densification without protection ensues. As water and the inherent risk are buried and repelled ever more intensively, the notions of hazard, risk and vulnerability become minimized or even completely erased from political consciousness and local populations. The latter, no longer aware of the danger involved, do not develop a home adapted to the risk of flooding, nor do they know what behavior to adopt in the event of a climatic episode.

The second weakness results in "the frequent difficulty of the territories to manage, maintain, monitor and perpetuate their protection structures" [3]. Indeed, the cost of setting up and then managing and maintaining these infrastructures is colossal. The dike heritage is consequently largely in a degraded state, no longer achieving its initial objective of protection. "In France, one of the most dammed up countries in Europe, seventy percent of the budget dedicated to flood risk management is nevertheless still devoted to the construction, strengthening and raising of these dikes" [3]. Vicious circle of this embankment campaign since it only increases the maximum flow rate of the water and therefore the pressure exerted on the dikes which are more and more weakened and degraded [7].

At the same time, the phenomenon of global warming will also highlight the limits of this flood risk management strategy. Indeed, as explained to us by Gautier [8], due to the increase in the average temperatures of the atmosphere on the one hand which causes the melting of the ice, and the increase in the average temperatures of the oceans on the other hand causing the thermal expansion of the waters, the level of marine waters will be raised. Meteorological phenomena are already on the increase on the different continents. These events will be more and more frequent, fierce and extreme given the changes incremented by the global warming that we are currently experiencing. The infrastructures imagined decades ago on the basis of now obsolete data are therefore no longer commensurate with the risk that our territories are currently experiencing.

We have the technical capacity to build and tirelessly strengthen our dikes in order to make them reach ever greater heights. As Stépahne Hallegate [6] points out: "We can build walls six, eight or even ten meters long, but do we really want to?" This would inexorably tarnish the relationship we have developed with water for ages, so characteristic of our civilization. Moreover, the perception at the foot of these immense walls as a man living in the city, would take a whole new dimension and could give way to a grim feeling of crushing and imprisonment. 
Thus, these infrastructures, a legacy of our past, are no longer up to the new risks and challenges of the cities of the 21 st century. This management strategy is a dead end, we cannot just erect barriers. Adapting our flood risk management strategy with the objective of making our cities resilient is therefore necessary and must be accompanied by a rigorous analysis and an integrated conception of this risk at the scale of the territory coupled with raising awareness among the population exposed to this risk.

\section{TOWARDS AN ABSORPTION STRATEGY}

\subsection{The consequences of the "resist" strategy}

Strongly anchored in the territories, the landscape and management policies, particularly in Europe, this historic flood risk management strategy is far from harmless [3]. By taking place on the territory, these civil engineering infrastructures have in fact had serious consequences and modifications on our soil, our landscape and our biodiversity.

First erased from urban and sometimes even peri-urban landscapes in the 18th century for security, health and economic reasons, this cutoff between water and human societies was accentuated in the 19th and 20th centuries with the development of infrastructure for the water mastery [9]. Dams, dikes, banks, raising of quays, retention basins or even burial under pipeline constitute both physical and visual barriers in the landscape. They prevent any close contact with water for both people and biodiversity. Rather an astonishing and contradictory strategy for a society which has always sought to develop as close as possible to this essential component of human life. Over nearly 200 years, more than 45,000 dams have been erected across the world. These also have accentuated the phenomenon of coastal land recession since the sediments being blocked, they cannot reach the coast anymore [6].

The development of these engineering structures also greatly contributes to the artificialization of our soils. A double problem which resides on the one hand in the works themselves. Almost entirely in concrete as specified above, they will, by their simple implementation, contribute to the artificialization of our soils. On the other hand, the primary objective of this water mastery strategy being to preserve the territories threatened by flooding from natural hazards in order to valorize them, the land gained by their installation will very quickly be urbanized. This urban sprawl, emblematic problem of the second half of the 20th century in Europe, leads to a strong waterproofing of the soil [1]. Sometimes even reducing to void the infiltration of water into the different layers that make up the soil, the phenomenon of runoff appears or is accentuated in both urban and rural areas. These territories are therefore found in some cases and in another way, still and always vulnerable to flooding.

Biodiversity will also be strongly impacted by these flood risk management practices. The drying up of wetlands in the idea of being able to urbanize them as well as the development of drainage systems in the hygienic approach of the 19th century will contribute to the gradual disappearance of these environments and of the particular ecosystem that they constitute [10]. As the infrastructures developed do not present any support for the previously present biodiversity, it will gradually desert this concrete environment. Elements of discontinuity in rivers, they will also have an impact on hydro-systems. Isolating rivers and streams from their alluvial plain, the hydrological rhythm is increased. As the areas of natural expansion of water in the event of flooding are no longer accessible, the risk of flooding is therefore also accentuated [11], [12]. 


\subsection{Leads for an absorption strategy}

What if the solution was simply residing in the erasure of these "barrier" measures? What if it consisted, on the contrary, in accepting water as an integral component of the territory rather than containing it and pushing it away with the help of these all-concrete-clad structures?

Over the past 20 years, an alternative has been rising in the flood risk management policy: "Faced with the risks, the territories must adapt and become less vulnerable, more robust, more resilient, that is to say better able to cope with and recover from a catastrophic event" [3]. As Hubert [13] points out, this management encourages us to understand the city as a system and to anticipate on the one hand its possible disturbances and failures during a crisis episode but also on the other hand, to consider its ability to resist, to adapt but also and above all to recover one's functions after the crisis. Risk management, therefore, shifts from a strategy of resistance, established essentially on blind confidence in the various civil engineering works, thus encouraging urban development in total disregard of the existing risk, to an adaptation strategy, where the risk of the flood will be taken into account and integrated into any planning project. The heart of the management strategy therefore becomes territory planning with the design of devices ready to overcome any possible failure of the protective structures [3].

At European level, this paradigm shift is reflected in the creation of an "Inondations" directive. This encourages an essential adaptation of the territories by insisting on the need to "reduce the negative consequences of floods on human health, the economy, the environment and the cultural heritage" [3]. Some countries will therefore gradually develop a new strategy, allowing more room for water and by extension for nature, that of "living with water". It consists of the ingenious, thoughtful and conscious reception of water on the territory or certain portions of it, inducing an adapted design of these zones: natural banks gently sloping towards the water, landscaped floods expansion park, flood plains, etc. "This means that there should be no obstacle to the natural flow of water, because any obstacle, by slowing down the flow, leads to the raising of the water line and thus increases the vulnerability of upstream sectors" [4]. Urbanization and architecture will therefore have to be studied so that, even in the event of a flood, water can retain its place without endangering the populations present. "Cities are no longer pebbles and become sponges" [4].

The "Room for the River" project developed by the Netherlands in 2005 is part of this perspective. Colossal work, its objective was twofold: to reduce the risk of flooding by acting on the water levels of the reference flood and to improve consideration of the environment. In total, thirty different projects have been developed on the arms of the Rhine, the Meuse, the Waal and the IJssel with the common desire to restore water to its full extent [14].

By thus returning to the center of concerns and urban design, water is no longer perceived as a threat but rather as an opportunity, despite the risk it represents. This practice is also in line with the increasingly strong social demand in terms of nature. The fact of integrating this component again in the planning of the territory makes it possible to rewrite the relationship between people and their environment until then neglected. As explained previously, "[...] by the absence or the poverty of biodiversity on these works (of civil engineering), or by the elements of discontinuity of the watercourses that they can generate, they generally present an ecological "loss"” [12]. This new strategy therefore takes advantage of this desire for nature to enhance the connection of our towns and villages to their natural ecosystems.

These natural ecosystems, their biodiversity and above all the ecosystem services they provide, although too often neglected, are essential to human life. These ecosystem services are defined as "the benefits that human societies derive from functional ecosystems" [15]. 
Divided into four categories, they include production services, cultural services related to the environment of everyday life and well-being, support services and finally, regulation services such as climate and extreme event regulation. Ecosystems and living organisms therefore contribute in particular to "cushioning natural disasters by limiting the damage caused by floods, hurricanes, tsunamis, landslides or even droughts while ensuring the maintenance of the quality of air, water and soil" [16]. Often invisible, these services are therefore taken for granted by most of us and are still very rarely taken into account in urban policies.

Through this new understanding of risk by absorption, other functions will be able to be questioned again: soil permeability, water cycle, preservation and development of biodiversity, reduction of the effects of heat islands, air quality, safeguarding ecosystem services, .... Nature will ultimately play a leading role in this new management strategy. In addition to promoting flood risk management, it will bring added value to the territory. Conceived and inserted under the prism of the concept of multi-benefits, it will be favorable both for human societies and for biodiversity.

\section{CASE OF THE DISTRICTS OF MONS AND VALENCIENNES}

The subsequent objective of our study is to be able to develop a strategic absorption plan leaving more room for water as described above, in the districts of Mons (Belgium) and Valenciennes (France). To achieve this and within the framework of this article, we will first attempt to provide a history of the evolution of these territories in their management of the risk of flooding and the space left to water over time. Secondly, a diagnosis of the current territory targeting its vulnerability to the risk of flooding and its resistance infrastructures will be carried out in order to establish possible adaptation leads for an inclusive risk management.

\subsection{Presentation of the study area}

The district of Mons is located in the province of Hainaut in the Walloon Region in Belgium while the district of Valenciennes is located in the northern department of the Hauts-deFrance region in France (Fig. 1). Both forming an integral part of the international hydrographic district of the Scheldt (DHI Escaut in French), the main waterways crossing them are the Scheldt for the district of Valenciennes, the Haine and the Nimy-BlatonPéronnes canal for the district of Mons.

\subsection{History of flood risk management in the territory}

The international hydrographic district of the Scheldt has an essentially flat landscape. The rivers making up the district are therefore "of the lowland type with wide valleys and reduced flowrates and water flows" [17]. The changes that have taken place over time can be explained in particular by the fact that it is "one of the most densely populated and industrialized hydrographic districts in Europe" [17].

The Scheldt and its tributaries, mainly included in the Valenciennes district, are therefore low-sloping low-flowrates rivers, flowing into large floodplains with a flat profile and forming meanders. It therefore has a natural propensity to overflow. Over time, a large part of its meanders has been rectified and channeled in order to guarantee protection against flooding on the one hand and to promote navigation on the other hand [17].

In fact, from the 12th century, works to drain wet plains and to protect against flooding were carried out. These took place in "a context of population growth where the need for 


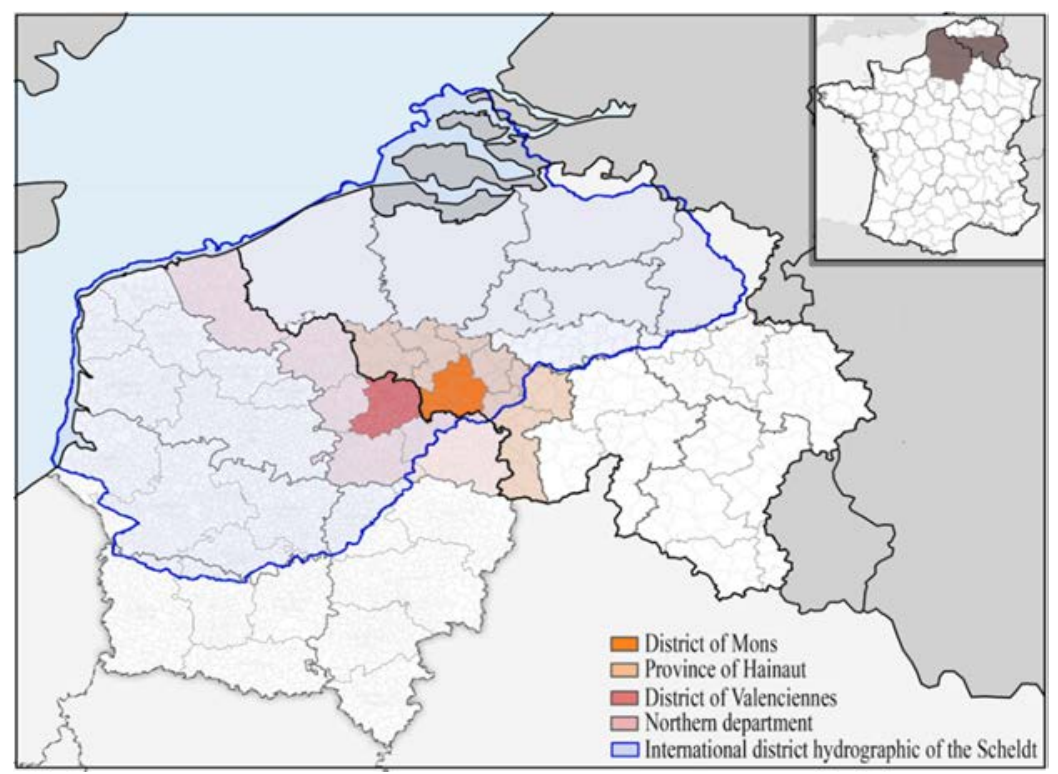

Figure 1: Situation of the districts of Mons and Valenciennes in the international hydrographic district of the Scheldt. (Source: Personal card produced on the basis of ISC-CIE data.)

arable land is increasing sharply" [2]. Many canals facilitating the rapid evacuation of water are therefore created, particularly and more frequently in the region of Condé, which is very humid and regularly subject to natural and military floods. The landscape of the Scheldt valley was finally completely crisscrossed in the 18th century by this ever-expanding hydraulic system of canals.

The industrial boom of the 19th century will in this case again lead to major works to modify the course of the Scheldt. Straightening of meanders, widening and deepening of its major bed, embankment, etc. so many actions carried out in order to control the flow of the river and make it navigable. Sounding the death knell for the presence of water in the urban centralities of the Valenciennes district, the gradual covering of rivers and urban canals in the 19th and 20th centuries completes this French containment policy developed in the name of flood protection and public sanitation [2].

The territory of the Mons district is also traversed on all sides by a river which will mark its development, La Haine. Characterized by a steeply sloping flow regime and a narrow valley on its middle and upper parts, navigation is only possible on its lower part, between Condé and Mons, where the landscape is relatively flat and the valley, very wide [18].

Already used in the 13th century for the transport of goods, it was quickly dammed and diverted for the first time in the 18th century in order to increase, just as with the Scheldt, the possibilities of flooding in the event of a siege [19]. Various dyking, damming and canal works will be carried out in the valley of Haine but, although it has always been prone to flooding and the region between Mons and Condé has always been swampy, the main works of engineering will rather be carried out in a commercial logic [20]. In fact, given the growing demand for coal at the dawn of the industrial revolution, the construction of the Mons-Condé canal at the beginning of the 19th century appears to be "an essential condition for allowing 
the Mons basin to fit into the large-scale waterway projects that emerged at that time" [21]. However, it will be filled a few years later in favor of the Nimy-Blaton-Péronnes canal, suitable for larger boats and also crossing the Montois district from side to side.

These various modifications of the landscape are not the only elements to have considerably complicated the flow of water in these two regions. Intensive mining brought an upheaval in the physical geography and completely changed the hydrographic regime of the two valleys. Sinking basins gradually formed and needed, mainly on Belgian territory, the raising of the banks, the containment of numerous rivers but also the installation of numerous pumping stations in order to raise the sewage, drainage and runoff waters and thus protect the entire Mons valley from flooding [18]. This irreversible phenomenon of the collapse of rocks, initially soaked in water, is called subsidence.

\subsection{The "resist" strategy in action on the territory}

At present, the major hydrographic network of the Mons and Valenciennes territories is totally artificial or largely modified (Fig. 2). The only natural components are the various minor tributaries of the Scheldt and the Haine. They generally match with a weak urban development in their surroundings. It is therefore the proximity or not of Man which conditions the place of water within the territory and over time. It is also interesting to note that, while many measures have been put in place for the management of the flood risk in the districts of Mons and Valenciennes during the last decades, the DHI Escaut still considers the majority of the area as "Presenting a significant potential risk of flooding" (Fig. 3).

Another alarming observation: the ecological state of the hydrographic network studied (Fig. 3). Indeed, the DHI Escaut classifies rivers according to several categories ranging from "very good" to "bad". It is to be noted that no hydrological component is included in the "very good" category, only one being in the "good" category: the "Marre à Goriaux", a mining subsidence pond has declared a national biological reserve since 1982. While the

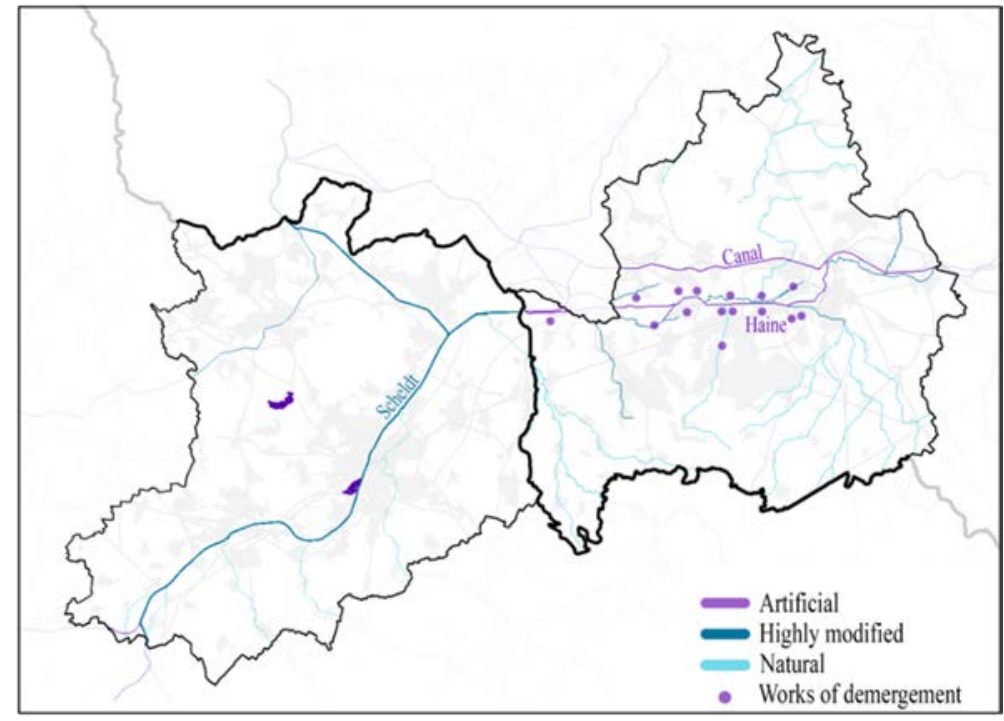

Figure 2: Status of surface water in the district of Mons and Valenciennes. (Source: Personal card produced on the basis of ISC-CIE data.) 


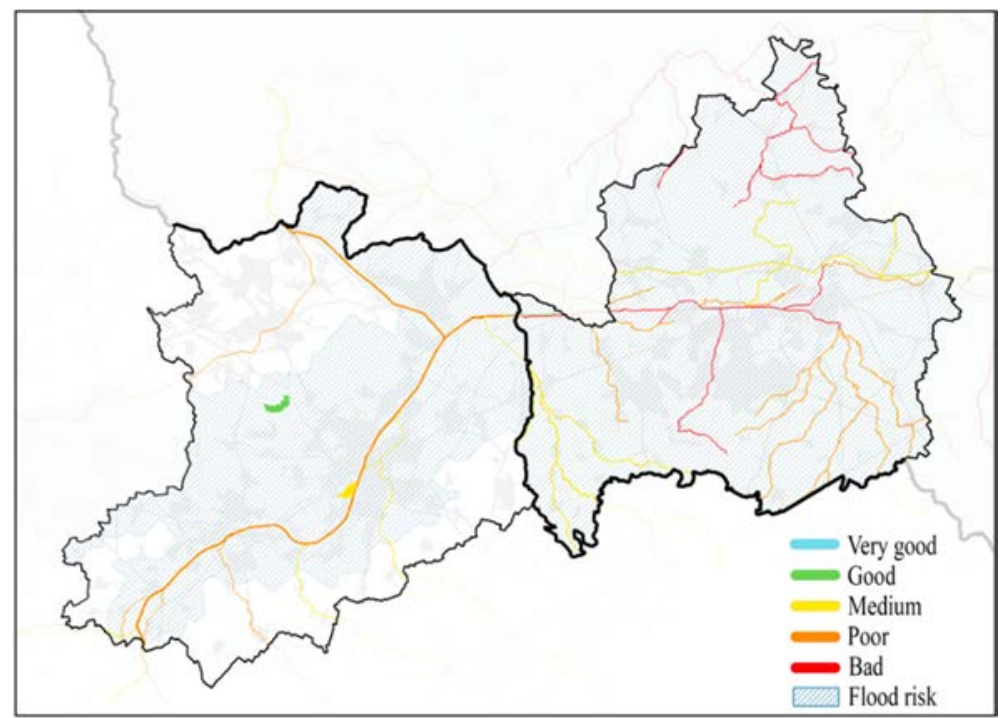

Figure 3: Flood risk and ecological state of surface water in the districts of Mons and Valenciennes. (Source: Personal card produced on the basis of ISC-CIE data.)

major watercourses such as the Scheldt and the Haine are included in the "mediocre" and "bad" categories due in particular to their strong waterproofing, one would have thought that the secondary water axes would have may have been of a higher quality than listed.

All the components of the hydrographic network should therefore be studied in order to reduce the potential risk of flooding while improving the ecological state.

\section{CONCLUSION}

Managing flood risk through adaptation has finally long been rooted in our traditions. From time immemorial, populations have not stopped adapting and reacting to the disasters they have experienced: dikes of earth, wood or stone, canals, .... The objective is always to protect the land as much as possible from invasion or rising waters to allow safe development of our societies.

The objective of this article was initially to be able to analyze the past by making a history of flood risk management over time and its "resist" strategy. The rise of the industrial period and the civil engineering infrastructures that accompany it only amplify this development, always closer to water as well as its damming, plunging into oblivion the inherent risk as well as the possible consequences, often dramatic, of the acts that we carry on the territory. Given the limits and consequences of these resistance structures highlighted throughout this article but also due to the increase in risk under the effect of climate change, we must now integrate the management of flooding risk in our development projects.

To complete this, a diagnosis, at present, has been carried out on the cross-border territory of the districts of Mons and Valenciennes to be able in the future of our study, to propose a more inclusive flood risk management and in full awareness of the risk incurred, by the use of multi-benefit nature both for human societies and for biodiversity. "Observe the present, know the past to anticipate the future" [22]. The diagnosis of the territory carried out within the framework of this article therefore consists of the first essential step in the implementation 
of a flood risk management strategy under the symbol of absorption on the territory of the districts of Mons and Valenciennes.

The aim is not to completely erase, on the entire territory, especially given the present phenomenon of subsidence, the artificial structures which are so many physical, visual, social and biological barriers. The aim is indeed to design flood risk management that reconciles human societies and their relationship with water and natural ecosystems.

The shift from a policy of "fight against" towards "living with" has already been initiated, to a greater or lesser extent, by certain nations. We just have to follow in their footsteps under the prism of "multi-benefit" nature. The next step in our study will therefore consist in determining what measures can be developed and applied in the cross-border study area to meet this new "living with" flood risk management strategy. Opening up of waterways previously buried underground, de-artificialization of canalized portions or even the creation of floodplains? Only the future will tell us.

\section{REFERENCES}

[1] Terrin, J.J., Renouvellement des approches urbaines face aux inondations. Villes inondables: prévention, adaptation, résilience, ed. Parenthèses, col. La ville en train de se faire, Marseille, pp. 12-27, 2014.

[2] Deudon, L., Pour une histoire des inondations et de la vulnérabilité dans la vallée de l'Escaut. Histoire et archéologie de la vallée de l'Escaut: Carnet d'Escaut, 2017. https://escaut.hypotheses.org/28.

[3] Bauduceau, N., Risque d'inondation et stratégies d'aménagement en Europe. Villes inondables: prévention, adaptation, résilience, ed. Parenthèses, col. La ville en train de se faire: Marseille, pp. 205-216, 2014.

[4] Peil, C., Hydrologie et projets urbains. Villes inondables: Prévention, adaptation, résilience, ed. Parenthèses, col. La ville en train de se faire: Marseille, pp. 234-247, 2014.

[5] Comité Français des Barrages et Réservoirs, L'histoire des barrages. Document technique, 2013. shorturl.at/iwHIJ.

[6] Mandy, M., Inondations: une menace planétaire, documentary, Géorama TV film production, 92 minutes, French, 2015.

[7] Barraqué, B. \& Gressent, P., La politique de prévention du risque d'inondation en France et en Angleterre: de l'action publique normative à la gestion intégrée. Rapport de recherche final, Université de Marne-la-Vallée, 2004. shorturl.at/egvA8.

[8] Gautier, Y., Inondations. Encyclopæedia Universalis. shorturl.at/CEHQ6. page consultée le 23/02/2016.

[9] Gralepois, M. \& Guevara, S., L'adaptation aux risques d'inondation façonnée par les métiers de la ville. Développement durable et territoires, 6(3), 2015. shorturl.at/fiyzO.

[10] Scarwell, H.-J. \& Franchomme, M., Autour des zones humides: espaces productifs d'hier et conflits d'aujourd'hui. VertigO, 6(1), 2005. shorturl.at/ktKQU.

[11] Scarwell, H.-J. \& Laganier, R. Chapitre 2: L'intégration matérielle du risque par le biais des mesures structurelles. Risque d'inondation et aménagement durable des territoires. Presses universitaires du Septentrion: Villeneuve d'Ascq, 2004. shorturl.at/diILO.

[12] Rey, F., Breton, V., Breil, P. \& Mériaux, P., Les solutions fondées sur la nature pour accorder la prévention des inondations avec la gestion intégrée des milieux aquatiques. Sciences Eaux \& Territoires, 26(2), 2018. shorturl.at/tMUW2. 
[13] Hubert, G., Ville et inondation: une cohabitation délicate. Villes inondables: prévention, adaptation, résilience, ed. Parenthèses, col. La ville en train de se faire: Marseille, pp. 218-233, 2014.

[14] Room for the river programme, Dutch Water Sector. shorturl.at/cksO8. Accessed on: 17 Mar. 2021.

[15] Rives, F., Pesche, D., M2ral, P. \& Carrière, M.-F., Les services écosystémiques: une notion discutée en écologie. 2016. shorturl.at/syAHZ.

[16] Une biodiversité en plaine santé pour nous protéger des catastrophes naturelles. BeBiodiversity. shorturl.at/hozDH. Accessed on: 15 Mar. 2021.

[17] Le district hydrographique international de l'Escaut, Comission internationale de l'Escaut. shorturl.at/jxGN8. Accessed on: 15 Mar. 2021.

[18] Annales des mines, Le démergement en Wallonie. 1998. shorturl.at/bfnHM.

[19] Hallez, M., Villes et villages de la vallée de la Haine - Mons. 2017. shorturl.at/xDJLM.

[20] Tison, L.-J., La lutte contre les inondations en Belgique. Ciel et Terre, 55, pp. 47-55, 1939. shorturl.at/sRV36.

[21] Honnoré, L., La canal de Mons à Condé: projets, financement et réalisation. Revue du Nord, 4(387), pp. 813-838, 2010. shorturl.at/auQS8.

[22] Delcourte-Debarre, M., Géohistoire du territoire forestier de l'Avesnois: observer le présent, connaître le passé pour anticiper le futur (France). VertigO, 16(3), 2016. shorturl.at/rxILZ. 